\title{
The Relationship Between Implementing Knowledge Management Practices in on-the-Job Training and Developing Professional Skills of Oil Industry Employees
}

\author{
Roushanak Rahmani ${ }^{1}$, Esfandiar Doshmanziari ${ }^{2}$ \& Nasser Asgari ${ }^{3}$ \\ ${ }^{1}$ Islamic Azad University, E-Campus, Islamshahr, Iran \\ ${ }^{2}$ Faculty of Management and Accounting, Islamic Azad University, Islamshahr, Iran \\ ${ }^{3}$ Faculty of Management, Shahid Sattari Air University, Tehran, Iran \\ Correspondence: Esfandiar Doshmanziari, Faculty of Management and Accounting, Islamic Azad University, \\ Islamshahr, Iran.
}

Received: October 22, 2017 Accepted: February 1, 2018 Online Published: February 26, 2018

doi:10.5539/jms.v8n1p137 URL: https://doi.org/10.5539/jms.v8n1p137

\begin{abstract}
In the technology-based organizations that are active in oil industry, the enjoyment of the employees of the specialized knowledge and skills plays a determinative role in their vocational performance. Inter alia the various prerequisites for such specialized skills in the employees, the present study has dealt with the evaluation of the knowledge management effect. The current study paper is an applied research in terms of its objectives and it has been carried out based on descriptive-survey method. The study population included the operational workers of Naft-e-Shomal Excavation Company that reached to a total of 2000 individuals out of whom 322 individuals were selected as the study sample volume based on convenience method. The data collection tool was a standard questionnaire the reliability of which was evaluated based on Cronbach's alpha method and a value equal to 0.86 was obtained. The data analyses have been undertaken assisted by path analysis and t-test statistical examinations through taking advantage of LISREL software and SPSS software. The results indicated that all four practices of knowledge management (knowledge creation, knowledge storage, knowledge application and knowledge sharing) exert positive and significant effects on the employees' development of specialized skills. Also, it was figured out that the company is in a good status in terms of both of the abovementioned factors.
\end{abstract}

Keywords: professional skills, knowledge management, knowledge creation, knowledge storing, knowledge application and knowledge sharing, on-the-job training

\section{Introduction}

The pioneering companies have started joining to the knowledge process during the recent years and new concepts like knowledge work, knowledge worker, knowledge management and knowledge organizations are informative of the intensification of such processes. Utilizing such terms, Piter Druker informs of the creation of a new type of organization in which the power of mind rules in lieu the power of arm. Based on this theory, the type of societies that can expect prospective development and progress are characterized by a more enjoyment of knowledge. In this way, the mere enjoyment of the natural resources cannot be as important as knowledge. Knowledge organization attains capabilities enabling it to make a huge power out of little force (Salavati, 2010, p. 108).

The knowledge in such companies is considered as the source of power and the knowledge management is applied to link those who have questions to those who have the answers to their questions. Knowledge management has been accompanied by the creation of creative and innovative groundings for these companies (Gazani, 2006, p. 2).

On the other hand, in the today's world which is called the world of change, variegation and rapid alternations, compliance to and keeping pace with the changes are the factors giving rise to the preservation of stability, persistence, growth and development and teaching is one instrument for safeguarding the adaptability of the organizational human resources to the daily increasing changes mentioned above. Undoubtedly, teaching is a precious means of developing the employees and it is of a particular specialty in improving the attitudes and 
discretion of the oil company employees as well as their occupational productivity (Monavvariyan \& Asgary, 2007). In the organizations that a greater weight is given to the HR training, the human resources are at any moment seeking to achieve novel practical solutions and information so as to enhance their productivity and efficiency and these organizations feature such characteristics as dynamicity, creativity and sublimity in the direction of creating effective changes in the intra-organizational factors and interaction with their immediate social environment. The main objective of the HRM (human resources management) is contribution to a better performance, to wit increasing the efficiency inside the organization for the accomplishment of the organizational objectives. Nowadays, a review of the experiences and researchers made by the others demonstrate that the abovementioned objectives cannot be fulfilled unless the organizational management acquires effective training goals in line with the continuous training of the human resources (Akhavan et al., 2012, p. 180).

In between, the mankind's development and progress in various aspects, including exploration and production of oil and gas resources, all owe to the mankind's knowledge. Knowledge management in the light of knowledge pervasiveness and expansion opens new venues to the world of mankind before the eyes. The understanding and perception of knowledge management is accompanied by a change of attitude in various individual, collective, organizational and global levels. The necessity for making a move towards a knowledge-driven society is the organizations and their employees' understanding of the knowledge management. For the time being, the importance of the KM systems in new knowledge sharing and creation has urged large oil companies around the world like Shell, British Petroleum, Texaco and others to make vast investments in this regard. Such a knowledge sharing, besides in the scientific and technical areas, will be of a great usefulness in such fields as HR (Gazani, 2006, p. 2).

Based thereupon, it can be stated that there is currently confirmed an undeniable role for the KM in improving the employees' performance and its positive effect on a great many of the training plans and systems has been discussed (Monavvariyan \& Asgary, 2007). But, there are yet aspects that have been less attended to up to the current point in time; therefore, the present study is seeking to systematically and empirically evaluate the relationship between the use of KM practices in on-the-job training and specialized skills training in regard of the oil industry workers.

The importance and the stance of the HRM in development programs of the oil industry reveal the necessity for codifying comprehensive plans regarding the application of various aspects of KM (knowledge management) in such an industry and this per se entails the investigation of various aspects of KM in relation to the increase in HR productivity. The findings of the present study can contribute to the development of theoretical knowledge concerning the KM role in accomplishment of the on-the-job training goals and it can also influence the effectiveness of the investments that are made in such areas as training and $\mathrm{KM}$ in industrial organizations.

\section{Literature Review}

\subsection{Staff Training}

Regarding the importance of training, it can be stated that training is an effective factor in the development of economical, social and cultural policies (Climent \& Cabrillana, 2012). Also, training causes industriousness, dutifulness, demonstration of innovation and creativity (Davis \& Hikment, 2008). Studies indicate that training influences the employees' attitudes (Sahinidis \& Bouriss, 2008), performance (Cheng et al., 2007), their creativity and innovation (Baridi, 2005) as well as their productivity and performance (Fitzgeral, 1992). Therefore, effective training can bring about organizational performance superiority and it also paves the ground for the employees' growth (Ivancevich, 2001). In the meantime, in-service or on-the-job training is considered as one of the most important organizational trainings because the occupational needs and the environmental conditions are in a constant change and such training can help the individuals adapt to the changes. In fact, the main objective of the in-service training is coordinating the individuals' needs and interests with the organizational needs and objectives so as to provide for the improvement of the individuals' performance in workplace via continuous acquisition of knowledge, skills and favorable attitudes (Orangi \& Gholtash, 2012).

While knowledge is recounted as the most valuable organizational capital, maintaining the employees and their valuable skills for the constant success of the organization is an inevitable necessity. Generally, employee retention is an important subject with which the organizations are faced and the issue is more vital regarding the knowledge workers who possess more valuable knowledge and skills (Mudler, 2001). Knowledge workers are considered as the most important organizational capital and their successful retention causes knowledge preservation and is a source of competitive advantage for the organization. Employee displacement and desertion can cause the organization to lose its knowledge sources as a result of which its competitive advantage suffers 
(Cappelli, 2000).

One appropriate solution for the retention of knowledge workers is offering proper and quality training programs to them (Mudler, 2001). The implementation of such programs will have a very important effect on the elevation of employees' loyalty to the organization and prevention from the loss of the knowledge storage and skill extant in the organization (Hallierand \& Butts, 1999). The reason behind such an issue lies in that the staff looks at training as an important factor for acquiring professional progress (Acton \& Golden, 2003). So, a great many of the organizations set elevation of staff loyalty to the organization and creation of proper culture for learning and training as the primary target of their training programs. Professional promotion is an important motivational factor for the knowledge workers and in case it is satisfied their loyalty will be more increased as a result of which the employee retention rates of the organization will heighten. Thus, it can be stated that the organizations' commitment to training the knowledge workers has a significant effect on their retention (Rnf \& Lord, 2000).

The organizations that give much value to training their employees spend a lot of resources on the training process so as to ascertain that the employees have received their required skills in the training programs; such organizations are successful in maximizing their training merits (Hung, 2001). Organizations that spend a lot of resources and efforts on training programs and skill development of their employees provide them with the grounding for continuous enhancement of the skills, elevation of knowledge transfer and positive psychological and organizational dynamicity and augment their competitive advantage, as well (Pate et al., 2000).

Generally, training points to the programmed efforts offered by the organizations parallel to facilitation of the staff learning regarding work-related competencies. These competencies include knowledge, skills and behaviors that are required for success at work. The objective in training the employees is developing the knowledge, skills and behaviors of interest in the training programs and emphasis on the use of them in getting the daily activities done. Nowadays, training does not solely incorporate the major skills; rather, it concentrates on the knowledge creation and knowledge sharing, as well. To acquire competitive advantage, training should be approached as a way to the creation of intellectual capital (Noe, 2003). Since the nature of the organizations' activities has changed and the knowledge working has found much importance in the organizations, the training programs offered to the employees should encourage continuous learning in them. Unrelenting learning necessitates that the employees have a full perception of the system as a whole. To do so, they are expected to be in a constant process of acquiring skills and knowledge and learn them and share them with the others (Noe, 2003).

Although, the organizational commitment to educate the employees is accompanied by optimum results, the success of the training programs entails the application of proper methods and solutions for the training of the employees. In methodological terms, the methods useful for an organization and/or an individual might be not appropriate for another organization and/or individual (Acton \& Golden, 2003).

\subsection{Knowledge Management Practices}

Knowledge management points to the a systematic and coherent process in line with the coordination of extensive activities of the organization including acquisition, creation, storage, appropriation and application of knowledge by the individuals and groups for the actualization of the organizational objectives (Rastugi, 2000, p. 42).

Knowledge Management Processes: knowledge is not a linear and static process. Quite inversely, it is a dynamic and cyclic process and it requires employees that are constantly in close contact with the information, acquire new knowledge and apply it for the reformation of the decisions (Gandhi, 2004, p. 460). By KM a type of process is intended that contributes to the organization in finding, selecting, organizing, distributng and transferring of information as well as to the activities like problem-solving, dynamic learning, strategic planning and decision-making (Gupta et al., 2000). Knowledge management processes of an organization should feature such a competency to be able to effectively and efficiently process the knowledge required for the actualization of organizational bsuiness processes. The individuals involved in knowledge processes have proposed vaious types of KM procedural models and the current research paper makes use of the procedural model proposed by Hicks (2000).

Knowledge Creation: it is connected to the learning ability and establishment of communication capability. In such a capability, the creation of relationship between the ideas and formation of cross-communications with the other issues are of key importance. Creation of knowledge is an endless process that includes creation of new knowledge or replacement of the extant knowledge by the implicit and explicit organizational knowledge. Knowledge is created via social and participatory processes as well as through individual cognitive processes inside the environment of an organization (Nonaka, 1994, p. 24). 
Knowledge Storage: it is the second element required for the knowledge management by means of which there is provided a possibility for performing rapid information searches, access to information by the other employees and effective knowledge sharing. Organizational knowledge storing, knowledge arrangement and knowledge retrieval, which is also termed organizational memory, constitute an important part of the KM. In this stage, the knowledge is stored and recorded so as to provide the organizational employees with the ability to retrieve and use it (Walsh \& Angson, 1991, p. 69).

Knowledge Sharing: this process contribtes to the development of a collective cooperation in which the individuals as colleagues feel associated and connected to one another in their actualization of their activities in their pursue of common goals. This process encompasses the distribution and dispersion of knowledge between the individuals and knowledge bases in a mechanized or nonmechanized bilateral manner. A high percentage of KM success depends on the correct exchange and sharing of the knowledge and the excahnge of the knowledge from an individual to anotehr is amongst the essential tools of the KM cycle (Radling, 2007, p. 179).

Knowledge Application: the fourth process begins in the idea that the knowledge creation can be more readily made feasible via objective use of the knowledge. This element completes the circle of the KM's central process. Knowledge application points to the idea that the ideas and the obtained knowledge can be utilized with no bias in terms of who has proposed them in case of their being appropriate and useful. This stage attends to blending knowledge with practice (Walkman et al., 2005).

\subsection{Knowledge Management and Employees' Training}

Since the predominant objective of the organziations in their application of KM processes is the enhancement of the employees' levels of knowledge, skills, techniques and experience, in this regard, it has a lot in common with the employees' training system that is in charge of training and enhacing the HR vocational knowlede and makiing it more sublime. Particularly, these relations are consideable and need to be scientifically studied in regard of the perspective that the purposive recognition and application of the employees' training and learning methods provide the grounding for the better understanding and acquisition and production and sharing of the knowledge between the individuals. It seems encessary to study these relations considering the shift in the role of the organizational training towards concentration on learning and acquisition, production and sharing of knowledge (Noe, 2008, p. 48) and the necessity for performing knowledge work by the staff and offering of ideas by the employees for the improvement of the services and production.

According to the theories given regarding the KM, the theoretical signs and symptoms of the relationship between KM processes and training methods can be discerned from the knowledge production and knowledge conversion ideas proposed by Nonaka and Tacuchi. According to the theory proposed by Nonaka and Cano, the socialization process is the first knowledge production and knowledge conversion process in the model designed by Nonaka and Tacuchi based on which the implicit knowledge is exchanged between the individuals and it entails a type of direct relationship between an individual and his or her colleagues and the organizational environment as well as the existence of a face-to-face relationship between the individuals and necessitates the teaching and learning method through observation, apprenticeship and coaching (Konno, 1998, pp. 40-47). In the externalization process, i.e., the conversion of implicit knowledege to explicit knowledge, such methods as written training, conceptualization, language of metaphor, interview and discussion and conversation help acquistion and sharing of the knowledge between the individuals (Dalkir, 2001, p. 65) Virtual teaching methods, the use of technology and database have been pointed out as useful methods in the process of explicit knowledge combination, acquisition and sharing. The method of training via continuous self-improvement based on on-the-job training and learning via performing and extracurricular programs have been pointed out as effective methods in the process of internalization and explicit knowledge conversion to individual implicit knowledge (Dalkir, 2001, p. 67). There are several studieds carried out inside the country including the researches conducted in scientific, research and technology institutions like the National Petrochemistry Company, Saipa Yadak and the Petrochemistry Research and Technology Company that are indicative of the idea that investing on the individuals and increasing the human capital (knowledge, experience and skill) via training the employees cause an increase in the organization's social capital and elevation of the organization's ability in knowledge production (Dalkir, 2001, p. 69).

\subsection{Conceptual Model}

Based on the literature cited herein, the present study considers the fourfold intervention of knowledge management as the independent variable and the staff's specialized skills as the dependent variable. Knowledge management embraces four practices: knowledge production, knowledge storing, knowledge sharing and knowledge application. These practices are borrowed from the model proposed by Hicks (2000). By the staff's 
specialized skills, the entire array of the technical knowledge and skills required by the employees working in oil industry for the fulfillment of their vocational duties is intended.

The relationship between the KM brand and specialized skills resulring from staff training is also assumed based on the findings of the study udnertaken by Noe (2008) who knows the objecties and the mechanisms of KM as overlapping with the staff training. Based thereon, the study conceptual model takes the form illustrated on figure (1).

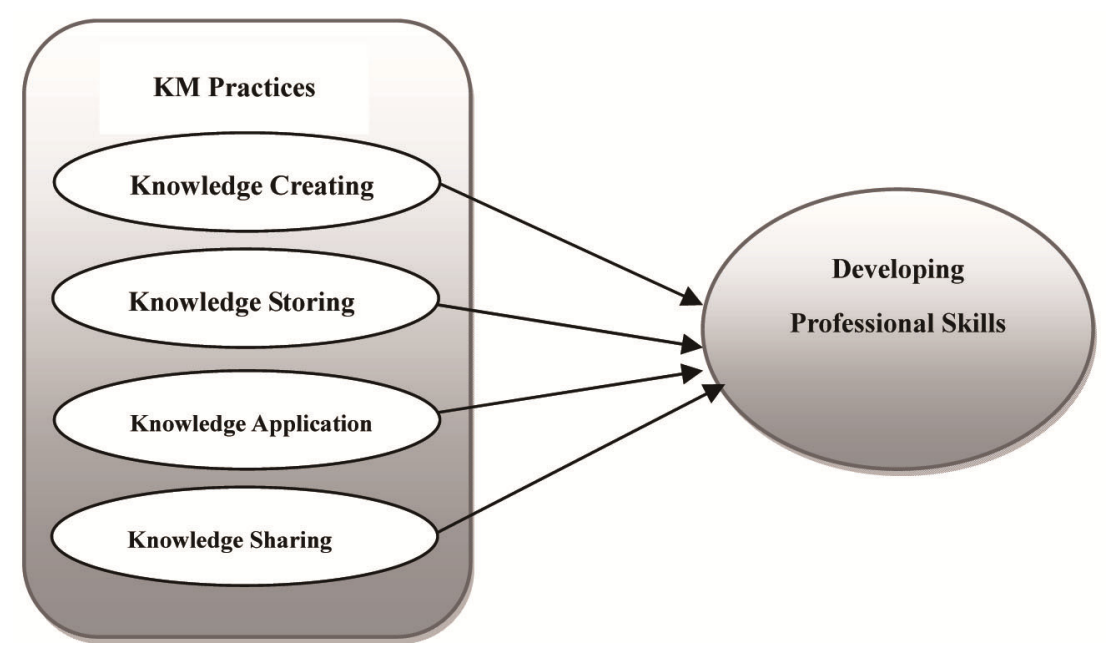

Figure 1. Study conceptual model

Considering mentioned issues and conceptual model of research about the impact of knowledge management practices on developing professional skills, hypotheses developed in this study include:

1). Knowledge creation has a positive and significant effect on developing professional skills.

2). Knowledge storing has a positive and significant effect on developing professional skills.

3). Knowledge application has a positive and significant effect on developing professional skills.

4). Knowledge sharing has a positive and significant effect on developing professional skills.

\section{Study Methodology}

\subsection{Study Method}

The present study is an applied research in terms of its objective; because, the results of the found herein are utilized to solve the special intraorganizational problems. In regard of the data collection method, the present study has been carried out based on a descriptive-survey method; because the required information has been obtained via investigating the status quo of the study sample volume. Also, in terms of the temporal considerations, the preset study is a cross-sectional research and it is a qualitative research, as well, in terms of the data type.

\subsection{Study Population and Sample Volume}

The study population evaluated herein included the employees working in Naft-e-Shomal Excavation Company with a total number of 2000 individuals. The present study made use of convenience sampling method. Also, according to the limited number of the study population, Cochran formula was applied to determine the study sample volume. The total number of the study sample volume based on the foresaid formula was 322 individuals.

\subsection{Data Collection Tool}

The instument used herein for the gathering of the preliminary field data was a questionnaire containing 25 questions that were scored based on Likert's five-point scale. To assess the knowledge management practices, there was made use of an adjusted Hicks scale (2000) (each indicator was measured by means of four parameters). To assess the staff's specialized skills, as well, ther ewas made use of a standard questionnaire designed by Eslami et al. (2010) that included 9 parameters. 
The questionnaire was exposed to face validity test. Also, a number of seven experts from the studied company confirmed the the questionnaire's validity based on a face validity evaluation.

To test the questionnaire reliability, a preliminary sample was administered thirty questionniares so as to run a pretest of the questionnaire and then the data obtained assisted by the use of SPSS software gave a value equal to 0.86 based on the Cronbach's alpha method as the confidence coefficient of the questionnaire. The reliability rates of the indices pertaining to each of the study variables are presented in table (1).

Table 1. Reliability coefficients of the questionnaire and each variable and its aspects

\begin{tabular}{llllll}
\hline Variable & Specialized skills & Knowledge creation & Knowledge storing & Knowledge sharing & Knowledge application \\
\hline Reliability coefficient & 0.76 & 0.79 & 0.74 & 0.81 & 0.83 \\
\hline
\end{tabular}

\subsection{Data Analysis Method}

To investigate the intervariable relationshis in the present study, path analysis tests were conducted within the format of study hypothesis and LISREL software was applied. One-sample t-test and SPSS softwre were also utilized to evaluate the current status of the variables in the studied company.

\section{Results}

Hypotheses tests were carried out by making use of path analysis in structural equations model. In this model, the relationships existent between the latent attributes that are extracted based on Hick's theory are evaluated according to the collected data (Kalantary, 2009). In the model investigated herein, there are 25 explicit variables (including the questions posited in the questionnaires) and five latent variables (the expressed independent and dependent variables). After modeling, in order to evaluate the model accuracy, there was made use of particular indices, including the chi-square to degree of freedom ratio that has to be smaller than a permissible value of three, the root mean square error of approximation (RMSEA) that has to be smaller than 0.08 and the pi value that should be smaller than 0.05 and the adjusted fir index that has to be larger than 0.9.

To investigate the significance of the KM practices' effects on the specialized skills, the significnace model was utilzied and a standard model was used to evaluate the amount of these factors' effects.

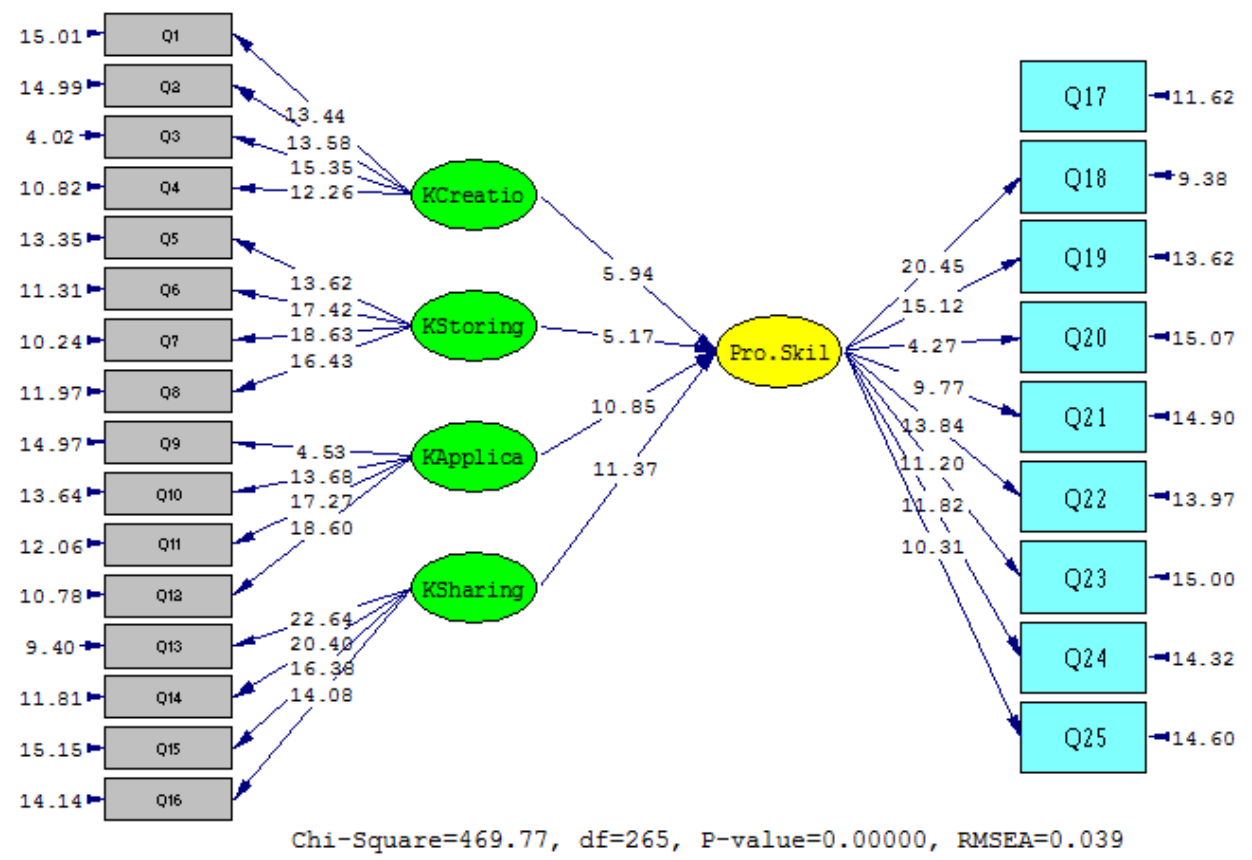

Figure 2. The impact model of KM intervention on specialized skills in a significant state

Regarding the significance of the figures obtained for the model, it can be stated that the hypotheses test has been carried out in a 0.95 confidence level, so those figures are significant that are not in a range from 1.96 to 
-1.96; based on the indices given in table (2), judgments can be made regarding the corresponding model's goodness of fit with the study conceptual model.

Table 2. The model goodness of fit indices pertaining to KM interventions' impact on the specialized skills

\begin{tabular}{llll}
\hline Indices & Permissible amount & Result & Evaluation \\
\hline$x^{2} \xi \boldsymbol{d} f$ & $x^{\mathbf{2}} \xi \boldsymbol{d f} \propto \mathbf{3}$ & 1.77 & Appropriate goodness of fit \\
RMSE & RMSEA $<0.08$ & 0.039 & Appropriate goodness of fit \\
\hline
\end{tabular}

The model's goodness of fit indices are indicative of the appropriateness of the model in mesuring the related variables; because the chi-square to degree of freedom ratio is equal to 1.77 and smaller than the permissible value, 3 ; the root mean square error of approximation, 0.039 , is in an allowed limit, i.e., it is below 0.08 . Based thereupon, the effect of the predicted relationships has been found statistically significant in all of the hypotheses because their values for the hypothesis one to four were more than 1.96.

Utilizing the standard model, the effects of the relationships whose significance has been confirmed can be evaluated. In other words, the model, in a standard state, indicates that to what extent each of the practices constituting the KM have exerted an influence on the development of the specialzied skills in the employees.

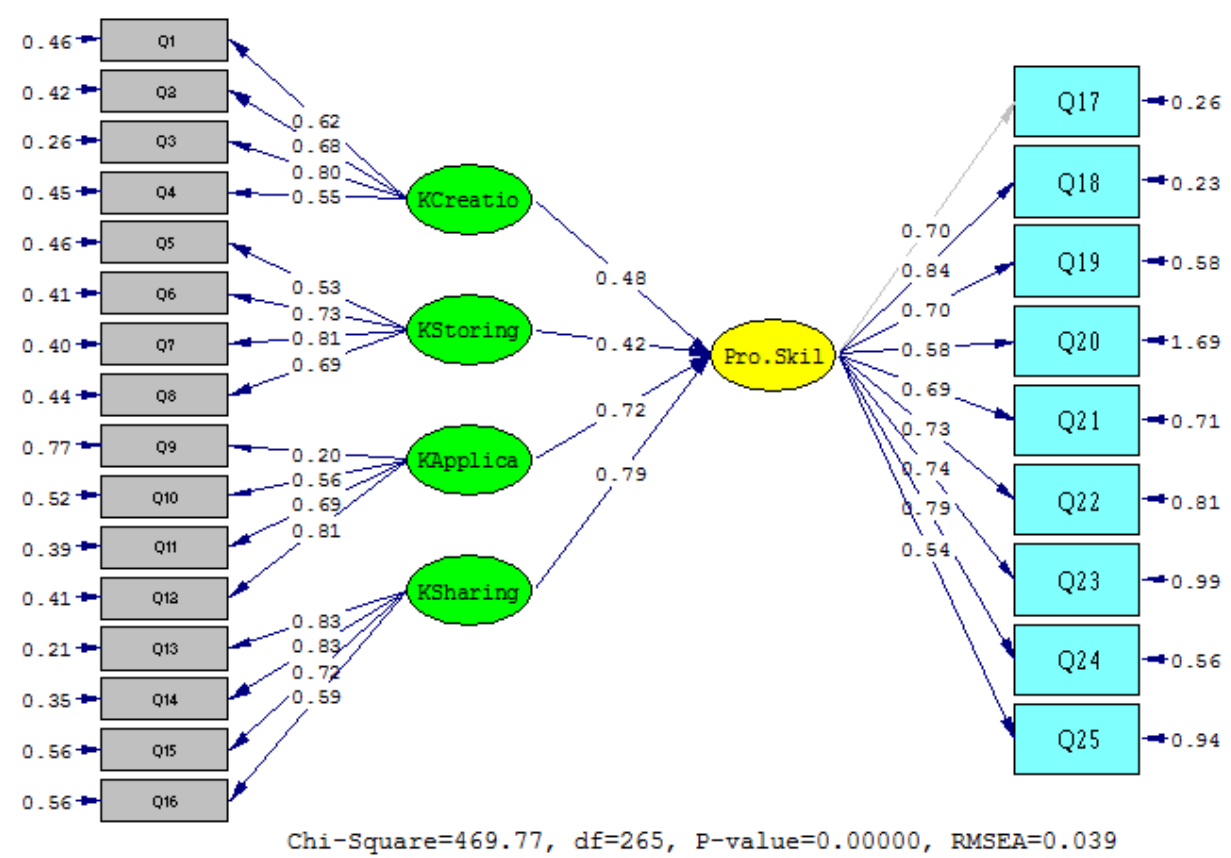

Figure 3. The impact model of KM intervention on specialized skills in a standard state

Figure (3) demonstrates the structural equations model (path analysis) pertaining to the study hypothesis in a standard estimation state. The standard coefficient obtained for the relationship between the knowledge creation (the first indicator of the $\mathrm{KM}$ ) and specialzied skills was equal to 0.51 that signifies the existence of a positive and significant correlationship between the two variables. Therefore, the determiantion coefficient (R2) obtained herein was equal to 0.26 that indicates the KM accounts for $26 \%$ of the specialzied skills variations. Similarly, the direct effect of the other practices constituting the KM (knowledge storing, knowledge application and knowledge sharing) on the development of the sepcialized skills in the employees can also be elaborated. The results thereof are summarized in table (3). 
Table 3. Hypotheses test results

\begin{tabular}{|c|c|c|c|c|c|}
\hline Hypothesis & Path: effect .... & $\begin{array}{l}\text { Signficance } \\
\text { values }\end{array}$ & $\begin{array}{l}\text { Standard } \\
\text { coefficent }\end{array}$ & $\begin{array}{l}\text { Determination } \\
\text { coefficent }\end{array}$ & Result \\
\hline 1 & Knowledge creation on the specialized skills & 5.94 & 0.48 & 0.23 & Confirmed \\
\hline 2 & Knowledge storing on the specialized skills & 5.17 & 0.42 & 0.18 & Confirmed \\
\hline 3 & Knowledge application on specialized skills & 10.85 & 0.72 & 0.52 & Confirmed \\
\hline 4 & Knowledge sharing on the specialzied skills & 11.37 & 0.79 & 0.62 & confirmed \\
\hline
\end{tabular}

The general pattern of the intervariable relationships proposed in structural equations model was found consistent with the hypotheses raised herein; all four investigated relationships were statistically significant. Based on the results obtained, the four practices comprising the KM were found having positive and significant effects on the specialized skills development by the employees. Also, according to these results, knowledge sharing had the highest effect on the specialzied skills development followed by knowledge application, knowledge creation and finally knowledge storage, respectively.

To investigate the appropriateness or the inappropriateness of the status quo of each of the variables studied herein in the study sample volume, the "population mean" test has been utilized. Since the SPSS software takes an equal state as the reference point in the investigation of the cutoff point, 3 in the present study, this latter one-sample mean test presents a larger-smaller form of the values in the hypothesis test so in lieu of the significance vlaues we will have upper and lower limits in this test of the study hypotheses exampination in such a manner that if two limits are found positive then $\mathrm{M}>3$ and the null hypotehsis will be rejected and the hypothesis will be confirmed accordingly; if both limits are found indicative of negative values then $\mathrm{M}<3$ and the null hypothesis will be confirmed and the contrary hypothesis will be rejected and finally if one limit is found positive and the other negative, $M=$ the test value, then the null hypohtesis will be again accepted and the opposite hypothesis will be rejected. The results of the tests are given in tables (4) and (5).

Table 4. One-sample t-test results

\begin{tabular}{lllll}
\hline Variable & Number of sumples & Mean & Standard deviation & Standard error \\
\hline Specialized skills & 321 & 3.64 & 0.683 & 0.038 \\
Knowledge creation & 321 & 3.58 & 0.682 & 0.035 \\
Knowledge storing & 321 & 3.72 & 0.692 & 0.036 \\
Knowledge application & 321 & 3.61 & 0.652 & 0.034 \\
Knowledge sharing & 321 & 3.78 & 0.697 & 0.039 \\
\hline
\end{tabular}

Table 5. One sample t-test results

\begin{tabular}{|c|c|c|c|c|c|c|}
\hline \multirow{3}{*}{ Variable } & \multicolumn{6}{|c|}{ Test value $=3$} \\
\hline & \multirow{2}{*}{ t-value } & \multirow{2}{*}{ Degree of freedom } & \multirow{2}{*}{ Significance level (2-tailed) } & \multirow{2}{*}{ Mean difference } & \multicolumn{2}{|c|}{$95 \%$ confidence interval } \\
\hline & & & & & Bottom limit & Upper limit \\
\hline Specialized skills & 7.31 & 321 & 0.000 & 0.644 & 0.451 & 0.784 \\
\hline Knowledge creation & 6.45 & 321 & 0.000 & 0.589 & 0.414 & 0.764 \\
\hline Knowledge storing & 8.17 & 321 & 0.000 & 0.726 & 0.550 & 0.901 \\
\hline Knowledge application & 7.37 & 321 & 0.000 & 0.619 & 0.453 & 0.785 \\
\hline Knowledge sharing & 7.64 & 321 & 0.000 & 0.634 & 0.472 & 0.796 \\
\hline
\end{tabular}

Based on the results obtained from the mean test of the population and according to the fact that the upper and lower limits of all four variables studied herein have been positive, so it can be concluded that the current status of the specialized skills in the employees and the components of KM are in appropriate in the studied company.

\section{Discussion}

According to the daily increasing importance that knowledge, as the most important organizational capital, has found, the retention of the knowledge employees and the mximum development of their learning capacities has been turned to one of the most important responsibilites of the HRM. One of the most effective methods of achieving such an important goal is offering proper and quality training to the employees because these employees consider training as a significnat factor contributing to their professional progress. 
Relative overlapping of the objectives and the KM mechanisms and employee training made us deal with the investigation of the role of the fourfold KM practices in employees' specialized skills development in a subsidiary company of the Oil Industry. The results obtained from the data analysis indicated that all four KM practices studied herein can exert a consdierable influence on the employees' specialized skills development. Im elucidates these relationships as bilateral ties between the training and $\mathrm{Km}$ in an organization. On the one hand, the human factor plays a key role in the KM process. The individuals' ability for work in new conditions and taking advantage of the extant knowledge and information and the transferring of them are factors determining the $\mathrm{Km}$ in an organziation. On the other hand, performing effective $\mathrm{KM}$ interventions in an organziation can enhance the knowledge, attitude, behavior and skill required by the employees for the effective fulfillment of their job responsibilities.

This finding is consistent with the results obtained by Piri et al. (2013), Seleim \& khalil (2011), Biransnav \& Rangnekar (2010), Mousakhani et al. (2013) and Chen \& Muhammad (2007). All of the above-cited studies have altogether emphasized on the role of KM in the HR development and the HR performance enhancemnt and insisted that KM can assist the knowledge and skill development in the employees for the elevation of their occupational performance levels.

To clarify the quality of such an effectiveness for each of the KM practices on the employees' development of specialzied skills, it can be stated that:

The first ancillary hypothesis underlines the role of knowledge creating in developing professional skills. The hypothesis being confirmed herein is indicative of the idea that the organziation should concentrate on the knowledge identification and offer proper accountability in order to corroborate and imporove the skills, knowledge, attitudes and behaviors of its human capital. To do so, the organization should before anything reach to the perception that its knowledge assets can create values for it. The organization should give weights to the knowledge, attitude, thought and choices of the clients and the employees. Also, the organizational senior managers are required to have a clear understanding of their intentions of implementing the knowledge management system and then provide support for its establishment. Afterwards, the organization should create the knowledge map system. Also, the strengthening and equipping of the knowledge base via creation of information banks that make it clear in what subject matters the clients and the staff possess special knowledge can play a role in this regard. Moreover, there is a need for the provisioning of a space in which the organization's human capital takes part in the knowledge identification. For instance, the employees can contribute to the organization in the identification of the approriate and inappropriate processes and procedures and show that what ideas can be acquire via appropriate procedures for the improvement of the inappropriate processes or procedures. The sturctural changes, including the creation of Research and Development units and taking the comparative and field studies' mission into consideration for the R\&D units, are also recommended.

The second ancillary hypothesis, reflects the role of knowledge storing in developing professional skills. In fact, the hypothesis indicates that knowledge, skill, attitude and behavior development of the employees can be strengthened via corroboration of knowledge storing in the KM system. To do so, the organizational managers shouls provide the employees with the required infrastructure for the creation of a teaching and learning environment. To create such an environment, the expansion and institutionalzation of the research culture and strengthening of the inquisition spirit in the employees can be served as proper solutions. The organziation should show it to the employees that this is effective in evaluation of their performances and service compensation. There is a need for the provisioning of the conditions that give rise to the encouragement of the employees for taking part in the intraorganizational and extraorganizational training courses. Also, the human resources of the organziation should be instigated to make use of the existing organizational resources and take advantage of the trustable individuals' counseling outside the organization so as to solve the work-related issues.

The third ancillary hypothesis underlines the role of knowledge in developing professional skills. In other words, confirmation of this latter hypothesis is suggestive of the idea that in order to improve and corroborate the HR attitudes, knowledge, behaviors and skills, the organization can take advantage of the knowledge development improvement in its KM system. Strengthening the knowledge development process before anything is in need of a correct understanding of the clients and the other stakeholders' needs and wants. Then, it is necessary to make adjustments between the organziational knowledge and these needs and wants. Next, the organizational knowledge is converted to the products and services based on the needs and wants. To better clarify the issue, it has to be stated in sum that the organization corresponds its knowledge with its external environment. In line with this, the corroboration of the environmental monitoring system and strategic conroling and increasing the organizational capabilities in regard of translating the internal organziational knowledge to value for the external 
environment through the ceation of effective and deep relationships between the units via adopting an approach toawrds the outside and the formation of service-providing units and interagency teams can be useful.

The forth ancillary hypothesis points to the role of knowledge sharing in developing professional skills. To actualzie the knowledge sharing atmosphere, the organizational managers should before anything show it to the HR via holding meetings, lectures, guidleines and other ways of the like that the knowledge sharing is not by any means a threat to them but it can also bring about an increase in their power and improve their positions. The organziation can expand network-like relations comprised of horizontal, vertical and transversal relations. This, per se, can be carried out via relying on the creation of formal and informal communication channels. As a specimen, the creation of the forums can be of an aid in this regard. Another issue with which the organization is faced is the way the knowledge and the experiences of the employees are recorded and transferred inside the organization. A considerable number of the employees have been working for more than 15 years in the studied organization and they will be retired in near future. The product of their long years of service is the knowledge and the experience that will be lost with the termination of their service period. Therefore, the organziation should have readied before it a specific strategy for the documentation and transferring of the knowledge held by these individuals and their similar counterparts in such a manner that the entire employees could have access to such knowledge and make their best uses thereof. Furthermore, the organziation should make greater efforts for the creation of teams and establishment of coordination and collaboration. The use of job tours in the organization in such a way that it can cause the publication of knowledge in the organziational units and interaction of experiences will be also of a great help.

\section{Reasearch Limitations}

The studies performed based on survey methods are inherently accompanied by complexities and limitations. The present study, as well, was faced with such restrictions. To gather the data in the current research paper, ideas and notions were acquired from the experts. The biases are not far from happening in such evaluations of the experts' ideas. Besides, the only instrument used for the data collection was questionnaire and due to the fact that there has not been made use of other methods like in-depth interviews, therefore the collected data lack the sufficient depth. So, it is suggested that the future studies make use of qualitative methods for the collection and analysis of the data. Moreover, the present study has only been conducted on one company and therefore care should be taken in generalizing the findings. Thus, the repetition of the present study on the other companies and industries can assist a more authenticate comparison of the effects of the offered values. Finally, many mediatory and adjusting variables might be playing a role in the relationship between KM and the specialized skills; the idenification and elaboration of the role of these variables in the future researches can contribute to the advancement of the study achievements.

\section{References}

Acton, T., \& Golden, G. (2003). Training the knowledge worker: A Discriptive Study of Training Practice In Irish Software Componies. Journal of European Industiral Training, 27(2), 127-146. https://doi.org/10.1108/03090590310468958

Birasnav, M., \& Rangnekar, S. (2010). Knowledge management structure and human capital development in Indian manufacturing industries. Business Process Management Journal, 16(1), 57-75. https://doi.org/10.1108/14637151011017949

Cappelli, P. (2000). Managing without Commitment. Orginazational Dynamicds, 28(4), 11-24.

Chen, L., \& Mohamed, S. (2007). Empirical study of interactions between knowledge management activities. Engineering, Construction and Architectural Management, 14(3), 242-260. https://doi.org/10.1108/09699980710744890

Cheng, M. I., Dainty, A., \& Moore, D. (2007). Implementing a new performance management system within a project- based organization a case study. International Journal Performance Management, 56(1), 60-75.

Climent, A., \& Cabrillana, A. (2012). The role of educational quality and quantity in the process of economic development. Journal of Economics of Education Review, 31(4), 391-409. https://doi.org/10.1016/j.econedurev.2011.11.004

Dalkir, K. (2011). Knowledge management in theory and practice. Printed \& Pound in United State of America.

Davise, C. J., \& Hikment, N. (2008). Training as regulation and development: An exploration of the needs of

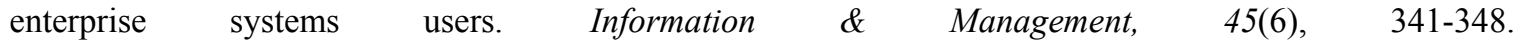
https://doi.org/10.1016/j.im.2008.04.002 
Fitzgerald, W. (1992). Training versus development. Training and Development Journal, 46(5), 81-84.

Gandhi, S. (2004). Knowledge Management \& Reference Services. The Journal of Academic Librarianship, 30(5), 45. https://doi.org/10.1016/j.acalib.2004.06.003

Gazani. (2006). Oil industry and knowledge management: application of KM in British Petroleum Company. Energy Economical Investigation, the International Energy Research Institute, 2(4).

Gupta, K. S. (2008). A Comparative Analysis of Knowledge Sharing Climate. Knowledge and Process Management, 15(3), 186-195. https://doi.org/10.1002/kpm.309

Hallier, J., \& Butts, S. (1999). Employers' discovery of training: self-development, employability and the rhetoric of partnership. Employee Ralations, 21(1), 80-95. https://doi.org/10.1108/01425459910253000

Hicks, S. (2000). Are you ready for management? Training and Development, 54(9).

Hunge, T. C. (2001). The relations of training practices and organizational performance in the small and Medium Enterprise. Education and Training, 5(8-9), 437-444. https://doi.org/10.1108/00400910110411620

Ivancevich, J. M. (2001). Human Resources Management. Companies. Inc.

Jessie Kong, M. A. (2009). A comparison of the practices used by human resource development. A professionals to evaluate web-based and classroom-based training programs within seven Korean companies' dissertation, The Ohio State University.

Monavvariyan, A., \& Asgary, N. (2005). The necessities of training knowledge workers in the knowledge-orientation era. Administrative Change, 48, 148-156.

Mousakhani, M., Hassangholipour, T., \& Vazifeh, Z. (2013). Offering a model for elaboration of the relationship between KM processes and the HR development in higher training. General Management Researches, 49-71.

Mudler, M. (2001). Custumer satisfaction with training preyrams. Journal of European Industrial Training, 25(6), 321-331. https://doi.org/10.1108/03090590110401791

Noe, R. A. (2003). Human Resource Management (4th ed.). New York: MgGraw-Hill Higher Education.

Noe, R. A. (2008). Employee training \& development (4th ed.). New York: MC Graw-Hill.

Nonaka, I. (1994). A dynamic theory of organizational knowledge creation. Ganization Science, 5(1). https://doi.org/10.1287/orsc.5.1.14

Nonaka, I., \& Konno, N. (1998). The concept of "Ba”. California Management Review, 40(3).

Orangi, A., \& Gholtash, A. (2012). Effectiveness of in-Service Education on staff and teachers in Shiraz. Quarterly journal of new approaches in educational Administration. Islamic Azad University Marvdasht, 2(5), 95-114.

Pate, J., \& Martin, G. et al. (2000). Company-based lifelong Learning. The Journal of High Technology Management Research, 11(2), 259-319.

Piri, M., Jasemi, M., \& Abdi, M. (2013). Intellectual Capital and Knowledge Management in Iranian Space Industry. The Journal of Information and Knowledge Management Systems, 43(3), 341-356. https://doi.org/10.1108/VINE-08-2012-0036

Rastogi, P. N. (2000). Knowledge management \& intellectual capital- The new virtuous reality of competitiveness. Human Systems Management, 9(1), 39-49.

Sahinidis, A. G., \& Bouriss, J. (2008). Employee perceived Training effectiveness relationship employee attitudes. Journal of European Industrial Training, 32(1), 63-76. https://doi.org/10.1108/03090590810846575

Salavati, A., \& Haghnazar, F. (2009). Analytical survey of the background factors influencing the KM system establishment in Iran's National Oil Company Headquarters. French Journal of Management, 10, 77-104.

Seleim, A., \& Khalil, O. (2011). Understanding the knowledge managementintellectual capital relationship: a two-way analysis. Journal of Intellectual Capital, 12(4), 586-614. https://doi.org/10.1108/14691931111181742

Wakman, K., Jansink, F., \& Streumer, J. (2005). The knowledgeproductive corporate university. Journal of European Industrial Training, 29(1), 40-57. https://doi.org/10.1108/03090590510576208

Walsh, P., \& Ungson, R. (1991). Organizational memory. Academy of Management Review, 16, 57-91. https://doi.org/10.5465/AMR.1991.4278992 


\section{Copyrights}

Copyright for this article is retained by the author(s), with first publication rights granted to the journal.

This is an open-access article distributed under the terms and conditions of the Creative Commons Attribution license (http://creativecommons.org/licenses/by/4.0/). 